\title{
Detection of Listeria monocytogenes in Pasteurized Milk Sold in Bogor and Its Relationship with Human Health
}

\author{
AGATHA WINNY SANJAYA ${ }^{1 *}$, MIRNAWATI SUDARWANTO' ${ }^{1}$, AND KIBUUKA ROBERT ${ }^{2}$ \\ ${ }^{I}$ Faculty of Veterinary Medicine, Institut Pertanian Bogor, Darmaga Campus, Bogor16680, Indonesia; \\ ${ }^{2}$ Faculty of Veterinary Medicine, Umutara Polytechnic University, P.O. Box 57, Nyagatare, Rwanda
}

\begin{abstract}
Many countries have established a zero tolerance policy, under which ready-to-eat foods are contaminated with Listeria monocytogenes at a detectable level. The research was done in two parts. The first part was to qualitatively identify the presence of $L$. monocytogenes in pasteurized milk ( $\mathrm{n}=32$ samples) sold in different supermarkets in Bogor. The method was adopted from the Bacteriological Analytical Manual/Food and Drug Administration. All samples tested resulted negative to L. monocytogenes. The second part of the research was to evaluate the growth of $L$. monocytogenes in sterilized milk stored in an incubator set at $4^{\circ} \mathrm{C}$ and monitored for 7 days. The original L. monocytogenes culture at a concentration of $1 \times 10^{9} \mathrm{cfu} \mathrm{mL}^{-1}$ was diluted with buffered

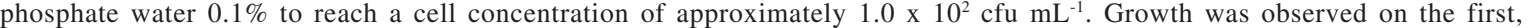
second, third, fourth and fifth day. On the sixth and seventh day, the numbers of colony forming units observed were almost similar $\left(2.5-2.8 \times 10^{5} \mathrm{cfu} \mathrm{mL}^{-1}\right)$. A population of 10 cells is sufficient to cause serious listeriosis infection in human.
\end{abstract}

Key words: Listeria monocytogenes, pasteurized milk, human health

Listeria monocytogenes is a foodborne bacterium recognized as pathogenic for human and animals, and is able to persist in the food industry environment for several years. Post-processing contamination of food with $L$. monocytogenes is a critical problem of public health. Several outbreaks of listeriosis were linked with the consumption of ready-to-eat foods (RTE) with a long shelf-live (Fraizer et al. 1988). Many countries have established a zero tolerance policy, under which RTE foods contaminated with $L$. monocytogenes at a detectable level are deemed adulterated.

The disease mainly affects pregnant women, newborn babies and adults who have a deficiency in their immune system. This fatal disease has a mortality rate of $25 \%$ and a hospitalization rate of $92 \%$. In human, L. monocytogenes is carried asymptomatically in the faeces of $2-6 \%$ of the general population. It is shed in high numbers $\left(>10^{4} \mathrm{~g}^{-1}\right)$ in faeces of infected people (Mc Lauchlin 1990). The organism is also considered to be potentially present in all raw foods and ingredients. Therefore, pasteurization is an important process in reducing bacteria present in milk so that it is safe for consumption. Much of the burden of illnesses was a result of inappropriate basic sanitation that occurs in food production, processing, retailing and handling at consumers' homes. The objective of this research was to detect the presence of L. monocytogenes in different brands of pasteurized milk sold in Bogor supermarkets, and the second research was to determine the number of colony-forming units in the sterile milk sample after 7 consecutive days kept in the refrigerator at $4{ }^{\circ} \mathrm{C}$.

\section{MATERIALS AND METHODS}

Sample Collecting and Handling. Samples collected were those of pasteurized high temperature short time liquid milk locally processed and packed in Indonesia. Samples were placed in an insulated cooler with ice packs, with a temperature range of $4{ }^{\circ} \mathrm{C}$ to $10^{\circ} \mathrm{C}$. Samples of four brands (A,B,C and D)

Corresponding author, Phone/Fax: +62-251-8625588, E-mail: awsanjaya@yahoo.com were collected from four supermarkets, namely Bogor Plaza (G), Hypermart (H), Ekalokasari Plaza (E) and Jambu Plaza (J). The collections were carried out twice in two weeks. Number of collection in every treatment was 8 .

The research was done in two parts. The first part was to qualitatively identify the presence of $L$. monocytogenes in pasteurized milk sold in Bogor supermarkets. Standard procedures were taken to ensure that all samples had not expired and that they were eligible for further process.

The second part of the research was to evaluate the growth of L. monocytogenes in sterilized milk stored in an incubator set at $4{ }^{\circ} \mathrm{C}$ and monitored for 7 days. The original L. monocytogenes culture (Field stem-Laboratory of Veterinary Public Health, Faculty of Veterinary MedicineIPB), at a concentration of $1 \times 10^{9} \mathrm{cfu} \mathrm{mL}^{-1}$ was diluted with buffered phosphate water $0.1 \%$ to reach a cell concentration of approximately $1.0 \times 10^{2} \mathrm{cfu} \mathrm{mL}^{-1}$.

Qualitative Analysis of Listeria monocytogenes. The method used to detect $L$. monocytogenes was adopted from the Bacteriological Analytical Manual/Food and Drug Administration (FDA 2003). It began with an enrichment of the sample in a Listeria enrichment broth, a buffered medium supplemented with Oxoid SR 141. After $24 \mathrm{~h}$ and $48 \mathrm{~h}$ of incubation at $30^{\circ} \mathrm{C}$, the enrichment culture was streaked with a Listeria selective media the oxford medium (OXA), which contains polymyxin B, acrilflavin and ceftazidime. After $24-48 \mathrm{~h}$ and seven days of incubation $\left(37^{\circ} \mathrm{C}\right)$, the OXA suspect colonies were seen as a black halo as a result of esculin hydrolysis, after which the five suspected colonies were streaked with tryptose soy agar and yeast extract (TSA Oxoid $\mathrm{CM} 131$ ), and incubated at $37^{\circ} \mathrm{C}$ for $24 \mathrm{~h}$. Presumptive Listeria isolates are based on a standard series of biochemical tests (Oxoid SR 141). The confirmation sugar test of $L$. monocytogenes isolates are rhamnose positive, xylose negative and CAMP test positive (Staphylococcus aureus ATCC 25723) with $\beta$-hemolysis enhanced in the vicinity of S. aureus. The suspected colonies were also subjected to potassium hydroxide, a motility test using SIM medium (Oxoid CM 0435) to detect the umbrella-like growth, 
Hydrogen peroxide and mannitol. The colonies from TSA with yeast extract were again re-streaked with tryptose soy broth (Oxoid CM 0435). A control positive was involved in picking a loop full of $L$. monocytogenes isolated from the field (Laboratory of Veterinary Public Health, Faculty of Veterinary Medicine-IPB) and mixed with Listeria enrichment broth in a clean and steril Erlenmeyer. A control negative was involved in the use of a loop full of Staphylococcus aureus with Listeria enrichment broth, and broth controls were run in the same manner as the test samples.

Inoculation of Listeria monocytogenes in Sterile Milk. A serial dilution of Listeria monocytogenes (isolated from the field) was done with buffered phosphate water (BPW $0.1 \% \mathrm{v} / \mathrm{v}$ ) to reach a cell concentration of approximately $1.0 \mathrm{x}$ $10^{2} \mathrm{cfu} \mathrm{mL} \mathrm{m}^{-1}$. One hundred milliliters of sterile milk was used as a test sample in each of the 8 clean and sterile Erlenmeyers. Then a $0.1 \mathrm{~mL}$ of $1.0 \times 10^{2} \mathrm{cfu} \mathrm{mL}^{-1}$ suspension was aseptically mixed by using a pipette into each of the 7 Erlenmeyers, coded E1 to E7. Code E8 was reserved for the control sample and was not inoculated. All the Erlenmeyers were stored in a refrigerated incubator set at $4{ }^{\circ} \mathrm{C}$.

Erlenmeyer E1 was removed after $24 \mathrm{~h}$ of incubation from the refrigerated incubator together with E8 as the control. Then $1 \mathrm{~mL}$ of E1 was aseptically poured into sterile Petri dishes labeled $10^{0}, 10^{-1}$ and $10^{-2}$ (all in duplicates), and $9 \mathrm{~mL}$ of BPW $0.1 \%$ was also prepared for dilution and $1 \mathrm{~mL}$ of E8 (control) was also prepared. Each of the Petri dishes was poured with a nutrient agar (Merck 105450) and homogenized thoroughly. All the plates were incubated at $37{ }^{\circ} \mathrm{C}$ for 24 to $48 \mathrm{~h}$. The control (E8) was returned to the refrigerator. After 24 to $48 \mathrm{~h}$ of incubation the colonies were counted and results recorded.

On the second day $1 \mathrm{~mL}$ of E2 was aseptically poured into Petri dishes labeled $10^{\circ}, 10^{-1}$ and $10^{-2}$, using dilution of $9 \mathrm{~mL}$ of BPW $0.1 \%$. The Erlenmeyer E8 (control) was also prepared and all dishes were poured with nutrient agar, homogenized and then incubated at $37^{\circ} \mathrm{C}$ for 24 to $48 \mathrm{~h}$. The research was continued, repeating the method of total plate count for E3 until the seventh day for E7 compared to the E8 as control. Descriptive statistics were used to describe the results. The results of the colonies counted per day were converted into logarithm and plotted against time in days.

\section{RESULTS}

Qualitative Analysis. In this research, L. monocytogenes was not detected in all samples tested. It can be concluded that L. monocytogenes was not present in the milk.

Quantitative Analysis. The growth of inoculated L. monocytogenes in a commercial sterile whole milk product was monitored at $4{ }^{\circ} \mathrm{C}$ for a period of one week, and the results obtained were shown in Table 1. On the first, second, third and fourth day there was no significant increase in the number of colony-forming units. However, on the fifth day a dramatic increase in the number of colony-forming units was observed. On the sixth day, a slight decrease in colony-forming units was noted when compared to that on the fifth day. On the seventh day the population of colony-forming units shot up, it is noted that an increase in the number of days has a strong
Table 1 Total Colony counts for L. monocytogenes in commercial steril milk stored in the refrigerator at $4{ }^{\circ} \mathrm{C}$ for 7 days

\begin{tabular}{ccc}
\hline Sample & $\begin{array}{c}\text { Periode time (days) } \\
\text { storage }\end{array}$ at $4{ }^{\circ} \mathrm{C}$ & $\begin{array}{c}\text { Total Microbes } \\
\left.(\mathrm{cfu} \mathrm{mL})^{-1}\right)\end{array}$ \\
\hline E1 & $1^{\text {st }}$ & $5.9 \times 10^{2}$ \\
E2 & $2^{\text {nd }}$ & $1.0 \times 10^{2}$ \\
E3 & $3^{\text {rd }}$ & $7.0 \times 10^{4}$ \\
E4 & $4^{\text {th }}$ & $1.0 \times 10^{4}$ \\
E5 & $5^{\text {th }}$ & $7.4 \times 10^{5}$ \\
E6 & $6^{\text {th }}$ & $2.5 \times 10^{5}$ \\
E7 & $7^{\text {th }}$ & $2.8 \times 10^{5}$ \\
\hline
\end{tabular}

relationship with an increase in the amount of $L$. monocytogenes.

\section{DISCUSSIONS}

Qualitative Analysis. Pasteurized milk is known to be one of the vehicles through which L. monocytogenes is transferred to human. Therefore many countries have initiated a zero tolerance policy prohibiting the sale of processed RTE food products contaminated with L. monocytogenes. This policy designates L. monocytogenes as a contaminant. Despite the imposed policy, the bacteria are constantly found in these foods. Vanderlinde and Grav (1991) found 2.4\% cases of Listeria spp. as a secondary contamination in different supplements. Dominguez et al. (1985) and Garcia and Vitas (2004) found a higher incidence of L. monocytogenes in pasteurized milk, $45.3 \%$ and $44.7 \%$ respectively, while Gül et al. (1994) from Turkey reported $1.1 \%$ found in samples of pasteurized milk samples. Farber et al. (1988) reported that $18.2 \%$ of raw milk in Ankara, Turkey, contained $L$. monocytogenes. Sharif and Tunail (1991) tested samples of pasteurized milk and they were all reported negative of L. monocytogenes. Based on all the findings mentioned above, it can be concluded that L. monocytogenes has a very low occurrence in milk. This does not mean that all the samples were free of L. monocytogenes. Other confounding factors may have played a significant role.

Mesophilic aerobic bacteria and lactobacilli overwhelming flora that are seen may prevent proliferation of Listeria. Some authors reported that Lactobacillus sake (Lb.706) and similar spp., produce bacteriosin and play a role in inhibiting proliferation of Listeria spp. (Johnson et al. 1989; Weis 1989). Stopforth et al. (2005) reported that L. monocytogenes does not proliferate in food with a high total amount of microorganism. The inhibitory effect on the growth of L. monocytogenes is mainly related to the microbiological composition of the raw milk, in terms of thermophilic Lactobacillus and yeast. Inhibition of L. monocytogenes is probably due to the interrelationship between the microbiological and chemical factors. It is also important to note that this research may not get positive result because the number of samples tested was small $(n=32)$. It was difficult to calculate the right sample size because the prevalence of L. monocytogenes in Indonesia remains unknown. It is also important to point out that this research should use an additional method such as the conventional cultural method (polymerase chain reaction and enzyme linked immunosorbent assay) concurrently. Those method are said to be of higher sensitivity. Moreover, the control of L. monocytogenes 
in pasteurized milk via HACCP is focused mainly on the selection of raw milk and the control of the processing, packaging, distribution and storage condition. Even though the pathogen is effectively controlled during pasteurization, its presence in the final product is possible because of a post-pasteurization contamination from various sources at the plant environment. At present, however, it is presumed that $L$. monocytogenes can be killed by heating to $72^{\circ} \mathrm{C}$ for at least $15 \mathrm{sec}$.

Quantitative Analysis. Listeria monocytogenes maintained its population relatively well in sterile milk stored at $4{ }^{\circ} \mathrm{C}$ (Table 1). This is because it is a psychrotrophic organism which grows at lower temperatures. The reason of the late growth of L. monocytogenes as shown in the graph is likely caused by initial shock which may lead to delayed recovery and growth. In this study the author also attributes this observation to the alteration of the physiological state of the organism caused by the sudden cold-shock which may result in additional lag phase. The cells become easier to recover as they adapt to the environment at the later stages. This model provides a dairy industry with a useful tool for effective management and optimization of product safety, and it can lead to more realistic estimations of pasteurizedmilk safety related risks. It can therefore be presumed that L. monocytogenes concentrations on the fifth, sixth and seventh days of milk storage in refrigeration temperature $\left(4^{\circ} \mathrm{C}\right)$ can be dangerous to human health in both the immunecompromised and the healthy individuals. A population of 10 cells is sufficient to cause serious listeriosis in the nonhealthy individuals (invasive form), but in healthy individuals (non-invasive form) it requires over $10^{5}$ cells.

Doyle et al. (2001) reported that L. monocytogenes grows in pasteurized milk with the amount increasing 10-fold in 7 days at $4{ }^{\circ} \mathrm{C}$; therefore, milk fluid that becomes contaminated after pasteurization and stored under refrigeration temperature may attain very high population of $L$. monocytogenes after one week. Therefore an inappropriate setting of temperature may further enhance the multiplication of bacterial cells. In relation to the above condition, Hayes (1996) noted that the organism reach a significant increase on the fourth and fifth days. Whereas the research obtained a drastic increase starting the fifth day, and the number increased unreasonably high on the sixth day. However, on day seven there was no difference in the number of colony forming units, when compared with those calculated on the sixth day. This could have been due to exhaustion of nutrients in the media and lack of space for multiplication. The importance of public health and sanitary handling during processing the RTE food, and to keep food under refrigeration temperature is one way of controlling organisms. A population of 10 cells is sufficient to cause serious listeriosis infection in human.

Effect on Human Health. According to the research findings, it can be assumed that the growth of $L$. monocytogenes is not affected by low temperature. Inoculation of 10 cells of $L$. monocytogenes into sterile commercial milk and then stored in a refrigerator at $4{ }^{\circ} \mathrm{C}$ for $7 \mathrm{~d}$, showed significant growth of the bacteria. Cells multiplication occurred on the first day; however, there was a decrease on the second day. On the third, fourth, fifth and sixth days, an exponential and rapid increase in the number of cells was observed. The number of cells on the $7^{\text {th }}$ day was not significantly different from that on the $6^{\text {th }}$ day (Table 1 ). This phase is known as the stationary phase. The minimum number of cells required to cause listeriosis is just $100 \mathrm{cfu}$ (Mc Lauchlin 1990) when compared with the cell populations obtained in the experiment.

Listeriosis almost always occurs because of the patient's predisposed immune deficiency. Currently the acquired immune deficiency syndrome (AIDS) could have the highest risk for listeriosis in the world. Patients who have had organ transplants, malignancy undergoing chemo therapy or chronic liver disease, will have a higher risk for listeriosis compare to the normal population. However, listeriosis can occur in healthy individuals, particularly during an outbreak.

Consumption of a product of this nature, which is contaminated with a few $L$. monocytogenes cells can result in an immediate outbreak of listeriosis. Adult patients with meningo encephalitis will develop headache, fever and confusion. There is an unusual predilection for the development of disease in the posterior fossa with cerebral and brain stem involvement (Dee and Lober 1986). Multiple cranial nerve palsies and ataxia frequently develop. Gastrointestinal symptoms were also common beside fever, vomiting and diarrhea prior to the development of invasive listeriosis (Schwartz et al. 1989). The mortality rate for listeriosis is still high $(25-30 \%)$ while in perinatal cases, the infant mortality rate is approximately 50\% (McLauchlin 1990).

All pasteurized milk samples collected from different supermarkets sold in Bogor which were local products were negative of L. monocytogenes based on the FDA method. The absence of the bacteria most likely happened because of the effective pasteurization process and the fact that there is no post-pasteurization contamination. The risk assessment reinforces past conclusions that food borne listeriosis is moderately rare even though it can lead to a severe disease.

Listeria monocytogenes can resist cold temperatures, as low as $4{ }^{\circ} \mathrm{C}$. Such temperature cannot inactivate the organism, even though other organisms can not survive. Every effort should be made to ensure that RTE foods with longer shelflife are totally free of L. monocytogenes, considering that few cells can multiply to very high numbers under refrigeration temperature.

The results of this study could assist the government to evaluate the adequacy and focus of current prevention programs. Moreover, the result could support the development of new initiatives to ensure that these programs protect the public health appropriately and the effectiveness of new strategies in minimizing public health impact on food borne listeriosis.

\section{REFERENCES}

Dee RR, Lober B. 1986 Brain abscess due to Listeria monocytogenes: case report and literature review. Rev Infect Dis 13:1108-10.

Dominguez RL, Fernandez Garayzabal JF, Vazquez Boland JA, Rodiquez Ferri E, Suarez Fernandez G. 1985. Isolation de microorganismos du genre Listeria à partir de latí cru destinë à la consommation. Can J Microbiol 31:938-41.

Doyle ME, Mazzotta AS, Wang T, Wiseman DW, Scout VN. 2001. Heat Resistance of Listeria monocytogenes: JFP 64:410-29. 
Farber JM, Sanders GW, Malcom SA. 1988. The Presence of Listeria spp. in raw milk in Ontario. Can J Microbiol 34:95-100.

[FDA] Food and Drug Administration. 2003. Foodborne pathogenic microorganisms and natural toxins handbook. Washington DC: FDA.

Fraizer WC, Westhoof DC. 1988. Food microbiology international. Singapore: Mc Graw Hill.

Garcia-JVA, Vitas AI. 2004. Occurrence of Listeria monocytogenes in fresh and processed foods in Navarra (Spain). Int J Food Microbiol 90:349-56.

Gül K, Suay A, Elçi S, Özerdem N. 1994. Incidence and isolation of Listeria species in raw milk. Türk Mikrobiyol Cem Derg 24:22-5.

Hayes PR. 1996. Food microbiology and hygiene. $2^{\text {nd }}$ ed. London: Elsevier.

Johnson JL, Doyle MP, Cassens RG. 1989. Survival of Listeria monocytogenes in ground beef. Int J Food Microbiol 6:243-7.

McLauchlin J. 1990. Human listeriosis in Britain, 1967-1985, a summary of 722 cases. J Epidemiol Infect 104:181-9.
Schwartz B, Hexter D, Broom CV. 1989. Investigation of an outbreak of listeriosis. J Infect Dis 159:680-5.

Sharif A, Tunail N. 1991. Investigation on Listeria monocytogenes contamination of raw milk obtained from different regions of Anatolia and pasteurized milk sold in Ankara. Mikrobiyol Bült 25:15-20.

Stopforth JD, Skandamis PN, Sofos JN, Davidson PM. 2005. Naturally occurring compounds-animal sources. In: Davidson PM, Sofos JN and Branen AL, editors. Antimicrobials in food. $3^{\text {rd }}$ ed. Boca Raton: CRC. p 453-506.

Vanderlinde PB, Grav FH. 1991. Detection of Listeria in meat and environmental samples by an enzyme-linked immunosorbent assay (ELISA). JFP 54:230-1.

Weis J. 1989. Vorkommen von Listerien in Hack-fleish. Tierärztl Umsch 44:370-5. 